\title{
Development, Persistence, and Variability of Upwelling Filaments off the Atlantic Coast of the Iberian Peninsula
}

\author{
R. Haynes, E. D. Barton and I. Pulingo \\ Marine Science Laboratories, School of Ocean Sciences, University of Wales, \\ Bangor Menai Bridge, Gwynedd, United Kingdom
}

\begin{abstract}
The development, persistence, and variability of upwelling filaments off the Atlantic coast of the Iberian Peninaula are examined by means of advanced very high resolution radiometer infrared imagery observed between 1982 and 1990. These observations indicate that the regime is broadly similar to that observed in the California Current system and is closely related to the large acale wind climatology of the mubtropical gyre. Upwelling generally starts in late May or early June and persists until late September or early October. In May or June, a narrow band of cold water of quite uniform width is observed along much of the west coast of the Iberian Peninsula. This band has a "fringed" appearance; that is it consists of many narrow "fingers" of cool water extending 20-30 $\mathrm{km}$ offshore. The major filament structures generally do not begin to form until late July or August. The filaments appear first as bulges in the upwelling front. These bulges grow offshore to form filaments that reach their maximum length $(200-250 \mathrm{~km})$ in September. The lengthe of the filaments gradually decrease until the filaments become relatively rare in late October.

Typically, five or six fully developed filaments are observed off the Therian Peninsula late in the upwelling season. Most of these are associated with major topographic features of the region, in particular the large capes which are common to the north and south of the peninsula. It is therefore postulated that the dominant dynamical processes related to filament formation off Iberia is topographic forcing. The exceptions are two major filaments commonly observed along the more regular coastline of northern Portugal. It is hypothesized that these filaments are formed by flow instabilities resulting in meandering of the southward flowing jet. These instabilities may possibly be initiated by the large capes of northem Spain.
\end{abstract}

\section{INTRODUCTION}

It has been recognized for many years that eastem boundary current regions are eddy-rich areas with much temporal and spatial variability in their flow fields [e.g. Wooster and Reid, 1963]. In the early 1980s these observations were reinforced with the identification of coldwater filaments in satellite imagery. These filaments are prominent, contorted tongues of cold, upwelled water which extend offshore hundreds of kilometers seaward from the coast in upwelling regions. The area in which filaments are found is termed the coastal transition zone [Brink and Cowles, 1991]. Filaments are separated from the surrounding warmer, oceanic waters by significant fronts and are typically much longer in the offshore $(O(100 \mathrm{~km}))$ direction than the alongshore direction $(O(10 \mathrm{~km}))$. They are associated with strong $\left(O\left(1 \mathrm{~m} \mathrm{~s}^{-1}\right)\right)$ offshore current jets [Kosro and Huyer, 1986]. The existence of filaments extending seaward from spatially intermittent locations along the coast is most conspicuous along the eastern boundary regions of the Pacific coasts of North and South America and off the Atlantic coasts of the Iberian Peninsula, NW Africa and SW Africa. Filaments have been most

\section{Copyright 1993 by the American Geophysical Union.}

Paper number $93 \mathrm{JCO} 2016$

0148-0227/93/93JC-02016\$05.00 extensively studied in the California Current system, where several large research programs, including the Coastal Ocean Dynamics Experiment (CODE) and the Coastal Transition Zone (CTZ) program, have been undertaken and their results widely published [e.g. the Journal of Geophysical Research, 92(C2), 1987, and the CTZ collection, Journal of Geophysical Research, 96(C8), 1991].

The observations both from Califomia and off Iberia [Haynes and Barton, 1990; this paper] indicate that the basic current regimes are similar and are closely related to the large-scale wind climatology of the subtropical gyres. In both regions during winter, when the winds are at their weakest or are downwelling favorable, the flow in the coastal transition zone (within about $100 \mathrm{~km}$ of the coast) is poleward. In summer, when winds are predominantly equatorward, the mean surface flow has an equatorward component and in accordance with classic Elman theory has a near-surface offshore transport giving rise to coastal upwelling. However, the detailed flow picture is more complicated. In the California Current system, filament formation appears to be associated with the unstable meandering flow of the California Current, which is embedded in a field of persistent eddies with which it interacts. The filaments represent the offshore trending limb of the meanders in which the cold upwelled water acts as a nonconservative tracer of the current path. The relative coolness of the surface waters is possibly a result of both 
coastal upwelling and in situ upwelling due to ageostrophic divergence of the current flow along the filaments. Nevertheless, it has also been observed that rapid sinking $O\left(25 \mathrm{~m} \mathrm{day}^{-1}\right)$ may take place at the strong temperature front on the filament boundary [Kadko et al., 1991; Washburn et al., 1991; Flament et al., 1985]. As water is advected offshore in the filament, near-surface warming gradually diminishes the temperature contrast with surrounding oceanic waters, so the retum limbs of the meanders have little or no temperature signature. The rapid offshore advection of surface waters is observed both by direct current measurements and by drifter trajectories [Brink et al., 1991; Davis, 1985, a, b; Huyer et al., 1991; Kosro and Huyer, 1986].

In this paper we describe the development, persistence and variability of upwelling filaments off the Atlantic coast of the Iberian Peninsula (Figure 1) observed by advanced very high resolution radiometry (AVHRR) satellite imagery between 1982 and 1990. In addition, we describe possible mechanisms of formation of the filaments and suggest likely generation mechanisms for each of the major filaments observed off Iberia.

\section{SATELLTte DATA and Processing}

The satellite data were collected onboand the National Oceanic and Atmospheric Administration (NOAA)-series weather satellites using AVHRR. The AVHRR is a scanning radiometer with five spectral bands, three of which are in the thermal infrared. $A$ combination of digital images, which were geometrically corrected and temperature corrected using the split-window algorithm of $\mathrm{McClain}$ et al., [1985], and monochrome prints representing channel 4 brightness temperatures was used in the filament analysis presented in this paper. An archive of over 800 brightness temperature scenes of relatively cloud-free AVHRR images provided by the University of Dundee satellite receiving station was built up for the years 1982-1990 (Table 1).

The positions, orientations and lengths of the filaments on the monochrome prints were measured using a combination of a scaled overlay of the Iberian coastline and a graticule with orientation and distance marked off. A degree of subjectivity was involved since although the origin of the filament at the coast was usually obvious, the offshore end of the filament was often diffuse, and an arbitrary point had to be chosen. Geometric distortions of the image due to Earth curvature and Earth rotation also give rise to errors in estimating the positions of the filaments. These errors mean that the coastal origin of the filament will be located to an accuracy better than $\pm 10 \mathrm{~km}$ but the offshore end of the filament can be approximated only to $\pm 20 \mathrm{~km}$. The orientation of each filament was measured to an accuracy of $\mathbf{\pm 5}$. The filaments were referenced to a Cartesian coordinate system with the positive $x$ direction toward the east and the positive $y$ direction toward the north, the origin being at $40^{\circ} \mathrm{N}, 10^{\circ} \mathrm{W}$.

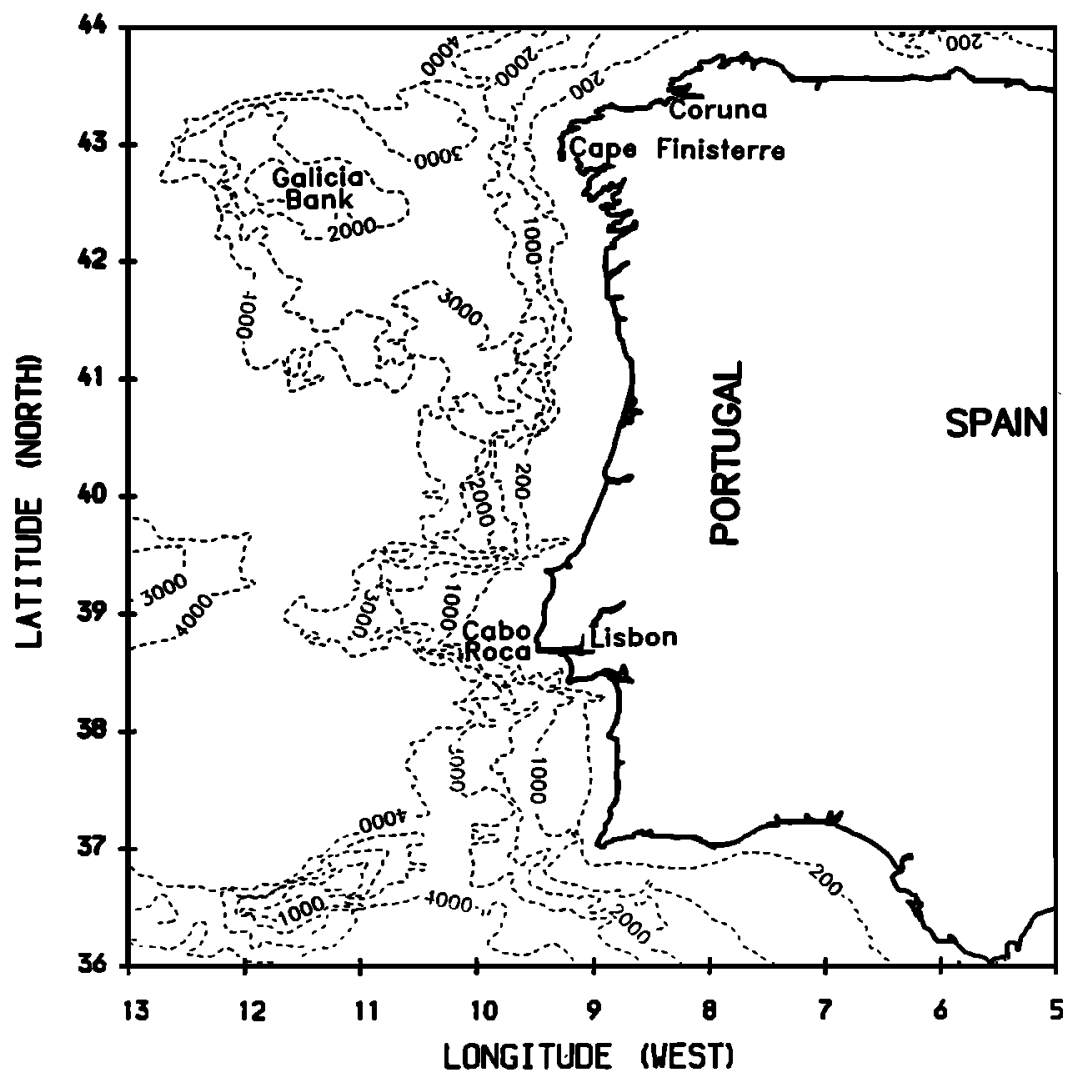

Fig. 1. Bathymetry of the Atlantic Ocean west of the Iberian Peninsula. The figure shows the large capes that dominate the coastline to the north and south of the perinsula and the three major east-west trending submarine ridges. 
TABLE 1. Summary of the AVHRR Monochrome Archive

\begin{tabular}{|c|c|c|c|c|c|c|c|c|c|c|c|c|c|}
\hline \multicolumn{14}{|c|}{ Number of Images } \\
\hline & Jan & Feb. & Mar. & Apr. & May & June & July & Aug. & Sept & Oct. & Nor. & Dec. & Total \\
\hline \multicolumn{14}{|l|}{ Year } \\
\hline 1982 & & & & & & 10 & 26 & 21 & 31 & & & & 88 \\
\hline 1983 & & 2 & 2 & & 2 & 2 & 1 & 2 & 2 & & & & 13 \\
\hline 1984 & 1 & 2 & 2 & 2 & 1 & 2 & 4 & 8 & 11 & 6 & 4 & 6 & 49 \\
\hline 1985 & 5 & 6 & 6 & 9 & 3 & 11 & 10 & 11 & 5 & 12 & 2 & 4 & 84 \\
\hline 1986 & 2 & & 9 & 7 & 7 & 9 & 10 & 14 & 20 & 10 & 7 & 8 & 103 \\
\hline 1987 & 7 & $\mathbf{s}$ & 11 & 6 & 13 & 9 & 8 & 10 & 11 & 2 & $\mathbf{1}$ & & 83 \\
\hline 1988 & 5 & 16 & 13 & 4 & 7 & 2 & 12 & 16 & 25 & 6 & 10 & 21 & 137 \\
\hline 1989 & 16 & 14 & 14 & 1 & 14 & 16 & 17 & 14 & 24 & 14 & 2 & & 146 \\
\hline 1990 & & & 12 & 14 & 23 & 16 & 24 & 21 & 14 & 11 & & & 135 \\
\hline Total & 36 & 45 & 69 & 43 & 70 & 77 & 112 & 117 & 143 & 61 & 26 & 39 & 838 \\
\hline
\end{tabular}

The availability of the cloud-free brightness temperature scenes (Table 1) introduces a regional and seasonal bias, which should be taken into consideration when analyzing and discussing the results. Owing to the meteorological situation off Iberia, the northem region is cloudier than the south as an effect of the passage of North Atlantic depressions, which impinge on the northern area more frequently. Early and late in the upwelling season, when the effect of the Azores high is not so well established over Iberia, the region is more subject to depressions and hence greater cloud cover. Interannual variations result in significant variation in the number of clear images available in any one year.

\section{SEASONAL EVOLUTION}

The seasonal evolution of the Iberian upwelling is closely related to the large scale climatology of the Northeastern Atlantic. During the summer months, when the Azores high-pressure cell is located in the central Atlantic and the Greenland low has diminished in intensity, the resulting pressure gradient forces air to flow southward along the coast of Iberia, a wind pattem that induces upwelling and an associated southward circulation. In contrast, in winter the Azores high pressure cell is located off the northwestern African coast and a deep low is located off the southeastern coast of Greenland. The pressure gradient between the two pressure systems results in an onshore wind with a component of wind stress northward off Iberia, although this mean winter wind pattem is modified by the energetic "depressions" typical of the North Atlantic during the winter months. The winter months are associated with the presence of surface poleward flow between the months of October and March [Haynes and Barton, 1990; Frouin et al., 1990].

The season of upwelling favorable winds off Iberia extends normally from May to October. In satellite imagery, brief episodes of nearshore upwelling are occasionally visible during winter in response to short-lived episodes of upwelling favorable winds. However, it is not until the onset of the summer Portuguese trades that persistent occurrence of cold upwelled water is visible.

In May or June, a narrow band of colder water, often of a quite uniform width, is produced along much of the coast. This band often has a "fringed" appearance or appears to consist of many narrow "fingers" of cool water extending $20-30 \mathrm{~km}$ offshore (Figure 2). If the winds relax or become unfavorable, that is, blow poleward, this narrow band may disappear temporarily and become reestablished later. The major filament structures do not generally begin to form until late July or August.

A sequence of images from 1982 (Plate 1) shows the later development of the structures. On August 9, nascent filaments were evident as bulges in the upwelling front at $42^{\circ} 30^{\prime} \mathrm{N}, 41^{\circ} 10^{\prime} \mathrm{N}$, and $40^{\circ} 20^{\prime} \mathrm{N}$. The upwelling front has the fringed appearance typically observed during the initial stages of filament development off Iberia. By August 20, the bulges extended offshore about $100 \mathrm{~km}$, and the structures now looked like filaments of cold upwelled water. The offshore progress of the filaments continued until about September 2, when the "nose" of the filament "anchored" at $42^{\circ} \mathrm{N}$ had migrated offshore approximately $200 \mathrm{~km}$. The offshore growth rate of the filament, or speed of the nose, was $O\left(10 \mathrm{~cm} \mathrm{~s}^{-1}\right)$. After September 2 significant warming commenced in the southern part of the region as a result of weakening of the winds. Cloud cover then increased, and the structures were not visible in images later in the year.

The statistical analysis of the archive of brightness temperature scenes illustrates the seasonal evolution of the filaments (Figure 3a). The filaments become common around the start of July (day 180), when they have a mean length of about $80 \mathrm{~km}$. During this period the mean width of the band of coastal upwelling is $O(50 \mathrm{~km})$, so the filaments extend $30 \mathrm{~km}$ seaward of the band of coastal upwelling. The filaments continue to grow over the following weeks until they reach a maximum mean length of $130 \mathrm{~km}$ in late September (day 270). The maximum observed filament length shows the same growth trend over a similar time period, with the maximum length increasing 


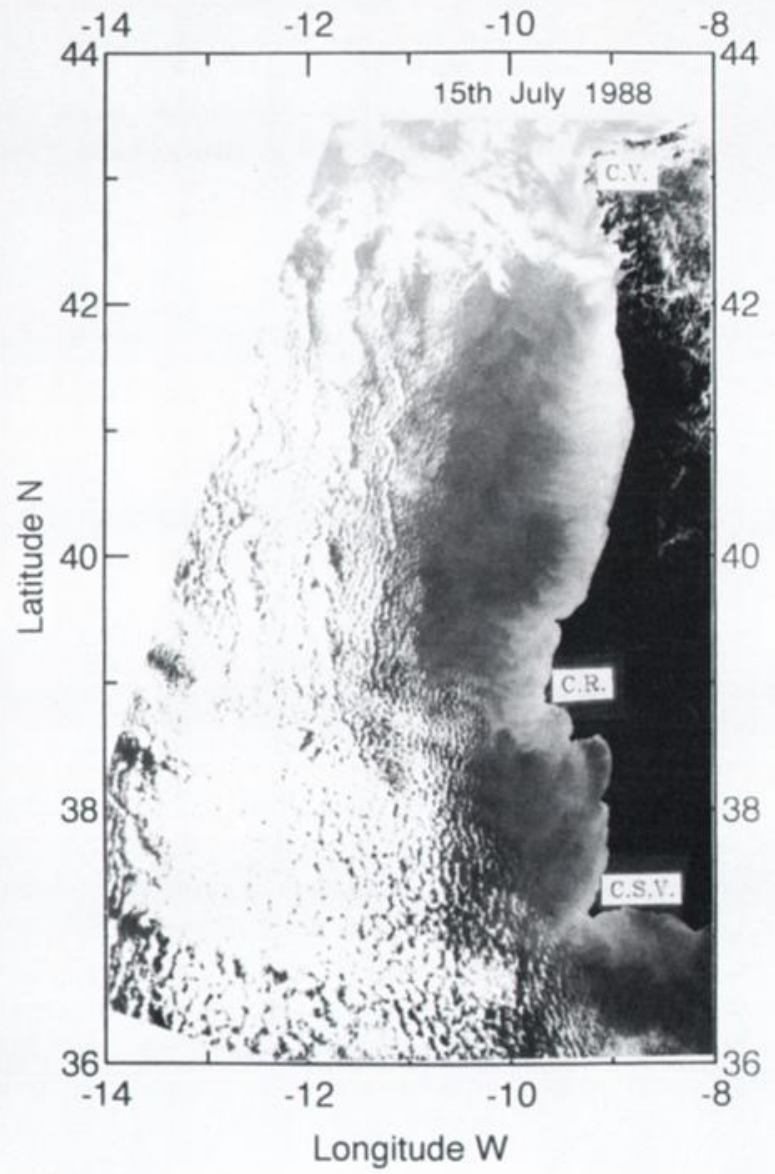

Fig. 2. A satellite image from early in the upwelling season (July 1988) showing the regular fingerlike pertubations that are a feature of the early atages of upwelling and filament formation. C.V., Cape Finisterre; C.R., Cabo Roca; C.S.V., Cabo São Vicente.

from approximately $120 \mathrm{~km}$ at the start of July to over 250 $\mathrm{km}$ in late September. After this, the length (both maximum and mean) of the filaments decreases until the filaments become relatively rare in late October (around day 300). The eventual fate of the filaments is not well documented, as cloud cover obscures the region when winds become upwelling unfavorable late in the year. However, it is believed that once active filament formation ceases (once upwelling stops), the near-surface waters warm bacause of insolation and subduction of the colder, denser surface waters. This process is likely to occur relatively quickly on a time scale of the order of a week.

The number of filaments observed (Figure 3b), which despite the biases discussed above probably correlates with the actual number of filaments present, shows the same trend as the observed lengths. Filaments become common in early July (day 180), reach their maximum frequency in mid-September (day 260), and then decline in abundance to become relatively rare by the end of October (day 300 ).

Plate 1. A weries of satellite images from 1982 showing the development and growth of filaments. (a) The coastal upwelling zone shows the regular fingerlike pertubations and nascent filaments. (b) The filaments have atarted to grow and extend seawards. (c) The filaments are almost fully developed and extend over $200 \mathrm{~km}$ from the coast.
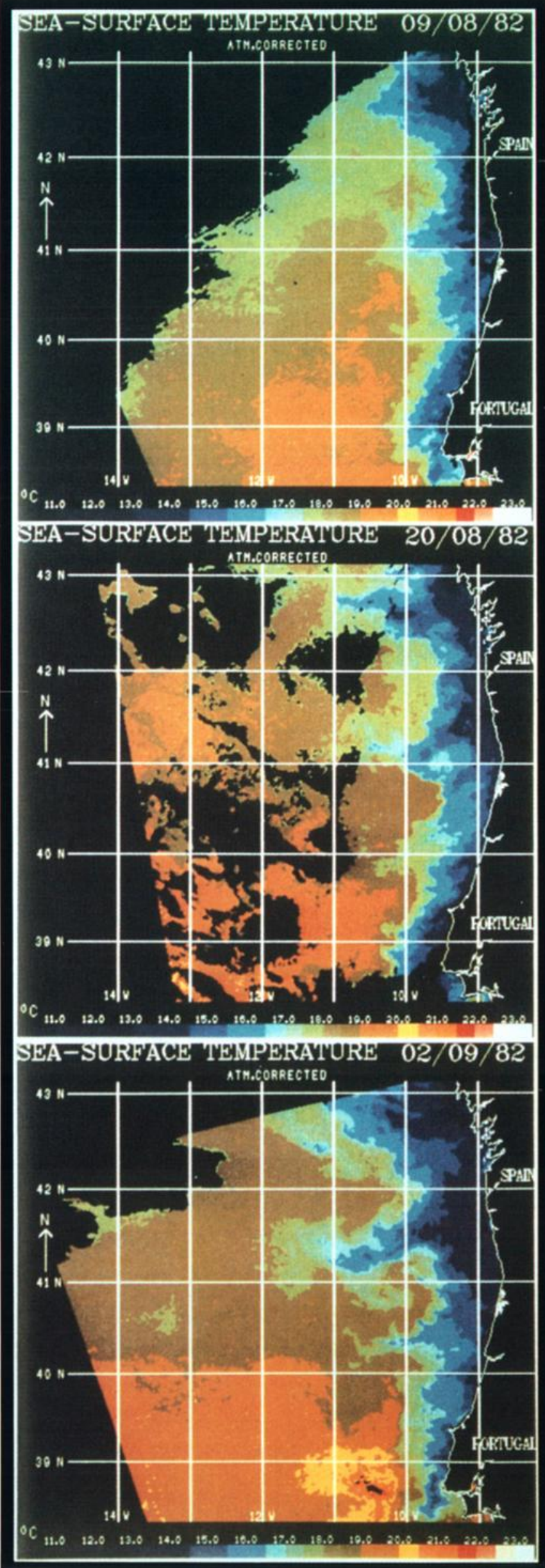
a MEAN TEMPORAL DISTRIBUTION

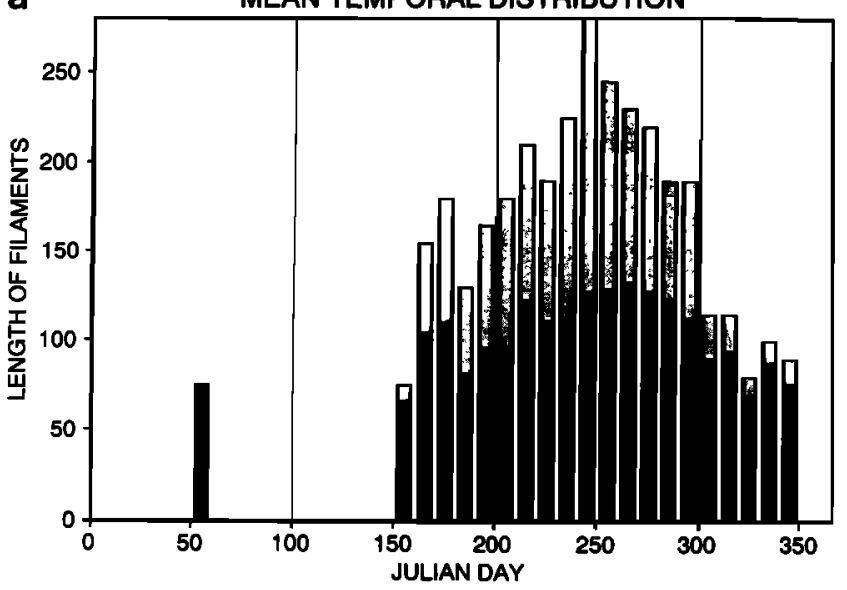

b MEAN TEMPORAL DISTRIBUTION

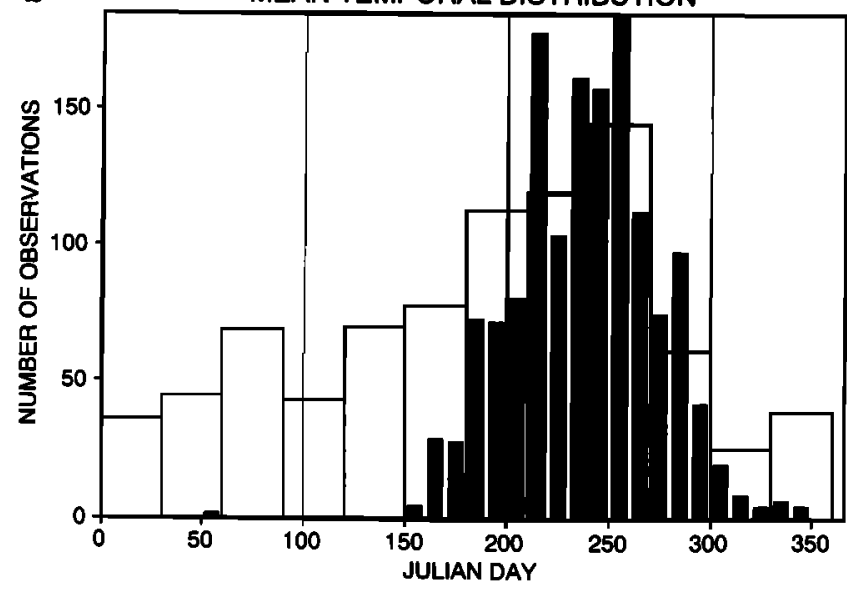

Fig. 3. (a) The temporal evolution of the mean length (solid bars) and greatest observed lengths (gray bars) of filaments from the brightness temperature scene archive (1982-1990). There is a gradual increase in both the mean and the maximum lengths of the filaments during the upwelling season from late May until late September. (b) The temporal evolution of the number of observed filaments per 10 day interval (solid bars) shows a gradual increase and then a decrease as the upwelling season progresses. The number of available images for 30-day periods (open bars) shows that although images are available in winter, virtually no filaments occur then.

The figures discussed above represent the sum of all the images between 1982 and 1990 . In most years, the filaments persist for 2-3 months, rarely longer, and so the mean observed picture is somewhat smoothed due to variations in timing and duration of the upwelling in different years.

\section{Spatial Distribution}

The spatial distribution of the filaments appears in most cases to be closely related to the coastal topography and bathymetry of the Iberian Peninsula and surrounding seas. Figure 4a shows the close correspondence between the major capes and the presence of filaments. Along the Galician coast (north of $250 \mathrm{~km}$ ), all the observed filaments appear to be associated with the multitude of large capes in the region. The two major sites, however, are Cape Finisterre (310-330 km north) and Cape Ortegal (390-410 $\mathrm{km}$ north). The other capes of the region are all observed to have filaments associated with them at some time or other, but these tend to be of both shorter duration and shorter length than the two filaments commonly observed at Cape Finisterre and Cape Ortegal. Similarly, along the southem part of the Atlantic coast of the Iberian Peninsula (south of $0 \mathrm{~km}$ ), all the major capes have associated filaments. In particular, Cabo Roca $(-140 \mathrm{~km})$, Cape Sines $(-220 \mathrm{~km})$, and Cabo São Vicente $(-330 \mathrm{~km})$ are common roots for filaments. Indeed, Cabo Roca is the most common filament location of all the large capes that dominate the Atlantic coastline.

In the intervening region between 0 and $250 \mathrm{~km}$ north, there is a rather uniform coast, with the exception of the small cape at $20 \mathrm{~km}$ north which occasionally has a small filament associated with it. When filaments are welldeveloped, this stretch of coastline with a relatively uniform
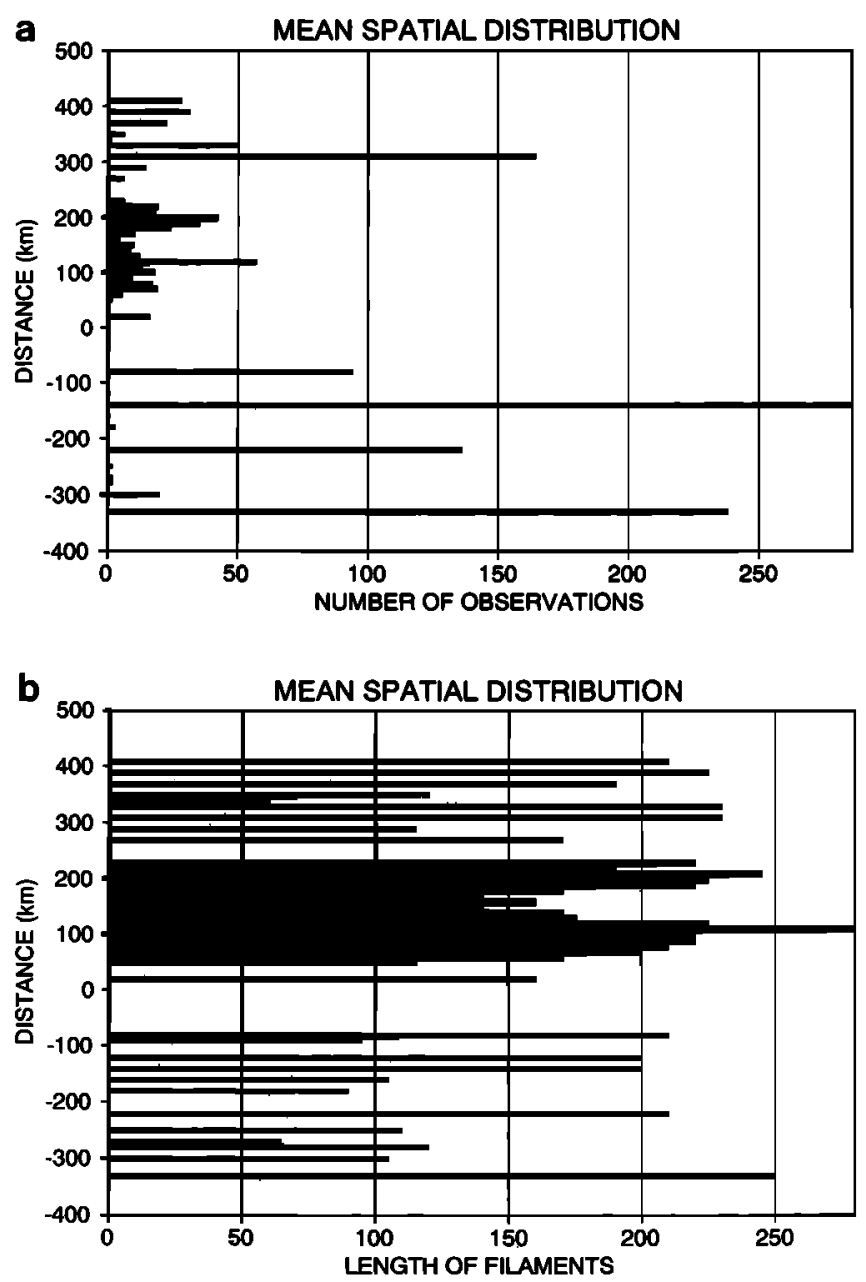

Fig. 4. (a) The spatial distribution of the coastal origins of all observed filaments (1982-1990), showing that filaments recur in a small number of localized regions, which generally correspond to major capes. (b) The mean (solid bars) and maximum (gray bars) lengths of the observed filaments (1982-1990) spatially related to the Iberian Peninsula. 
alongshore bathymetry is seen in the satellite imagery to be the origin of two large filaments. In Figure $4 \mathrm{a}$ the distribution of the origins of these filaments roughly approximates two overlapping Gaussian distributions with a mean separation of $80 \mathrm{~km}$, the maximums being at $200 \mathrm{~km}$ north and $120 \mathrm{~km}$ north.

In Figure $4 \mathrm{~b}$ these two filaments are seen to be the longest of all those observed off Iberia, both in terms of their mean lengths (150 km and $170 \mathrm{~km}$, respectively) and their maximum observed lengths $(245 \mathrm{~km}$ and $280 \mathrm{~km}$, respectively). However, the variation in filament length is not great along the coast. Maximum lengths are 200-250 kn for major filaments while the corresponding means are $100-150 \mathrm{~km}$. This latter figure of $100-150 \mathrm{~km}$ can perhaps be taken as representative of the width of the coastal transition zone.

\section{INTERANNUAL VARLATION}

From the AVHRR archive it is evident that filaments have appeared in every year since 1982. Images taken from different years (Figure 5) show that although any particular pattern is complex and there is great variability between images, a number of typical properties of the filaments can be observed.

1. Their maximum offshore extent is $200-250 \mathrm{~km}$, and their width can vary between 20 and $50 \mathrm{~km}$.

2. The edges of the filaments form strong temperature fronts $O\left(2-3^{\circ} \mathrm{C}\right)$ with surrounding oceanic waters that are often sharper on the equatorward side; these lateral boundaries are often the locations of baroclinic unstable waves.

3. The offshore limit of the filament may simply merge into the surrounding warmer waters or form a vortex pair. An example of the detailed development of a vortex pair is reported by Barton [1991].

4. Major filament sites are the Galician Capes (in particular Cape Finisterre), Cabo Roca, and Cabo Săo Vicente. Two other major filaments form commonly at latitudes $40^{\circ} 30^{\prime} \mathrm{N}$ (120 km north) and 4130'N (200 km north).

5. In some years the filaments extend almost directly west, while in others they are oriented more toward the south. At Cabo Săo Vicente the filament is sometimes observed even to bend around eastward into the Gulf of Cadiz.

Despite these similarities, there are large variations, both spatial and temporal, in the filament patterns in different years. Although this paper does not consider interannual temperature differences, recently published data [Afonso Dias et al., 1992] show interannual changes of over $4^{\circ} \mathrm{C}$ in monthly mean surface temperatures off southern Portugal between 1981 and 1987. The time series in Figures 6a, 6b, and $6 c$ shows that in some years the filaments may persist without interruption for up to 3 months (Figure $6 c$ ), in others they may persist only for a month or so, and in others they may appear episodically (Figure 6b). Temporary wind relaxations allow rapid surface warming, which quickly obscures the subsurface structure; on renewal of the wind, surface mixing removes the thin, warm surface layer to reveal the persisting underlying structure.
In 1982 (Figure 6a), the filaments (whose development is also shown in Plate 1) grew rapidly and uninterruptedly late in the upwelling season to reach the maximum size observed in any year. The development was rapid, with growth and decay occurring in less than 2 months. The orientation of the filaments changed from almost due west in the north to almost directly south in the south. This was the year in which the filaments exhibited their clearest development.

A contrasting year was 1986 (Figure 6b), which showed intermittent appearance of filaments over the entire summer and autumn without any consistent development. Greater organization and persistence of the filaments were apparent in the south, where the trade wind regime was probably stronger. The typical length of the filaments in 1986 was only about half that seen in 1982.

The year 1990 (Figure 6c) perhaps provided an example of typical development. Filaments appeared first in early June (after day 150) and developed fitfully during the summer, reaching their maximum length about the end of August (around day 250). Interruptions of their development, probably associated with periods of weaker, less upwelling favorable wind, were apparent around day 160 and day 260 and less prominently on other occasions. Development was not as consistent as in 1982; that is, filaments did not have the opportunity to grow to as great a length but were more pronounced than in 1986.

In brief, during years when the filament development persists uninterrupted for a month or more, they grow to the greatest lengths. These years are likely to be ones in which the Portuguese Trade Winds are well developed, without significant interruption by the passage of North Atlantic depressions. In years when the filaments are poorly developed or are episodic in appearance, the Portuguese Trades are likely to be weak or interrupted by the passage of North Atlantic depressions.

\section{Formation MEchaNISMS}

There are at least three theoretical possibilities for the formation of filaments [Brink and Cowles, 1991] including (1) dynamical flow instabilities, (2) topographic forcing, and (3) geostrophic turbulence (Figure 7). Now we consider each mechanism in more detail.

\subsection{Dynamical Instability}

Baroclinic instabilities inherent in the flows associated with upwelling, that is, equatorward surface jet and poleward undercurrent, could lead to the formation of filaments. Ikeda and Emery [1984], Barth [1989a], and McCreary et al., [1991] all argue that baroclinic instabilities associated either with the vertical shear between the equatorward surface flow and the poleward undercurrent or with frontal instabilities are responsible for the growth of filament structures.

In the paper by $\mathrm{McCreary}$ et al., [1991], a $2 \frac{1}{2}$-layer model simulates many of the observed features of the sea surface temperature field and the inferred flow field associated with it. Initially, the model spins up as a linear model, 

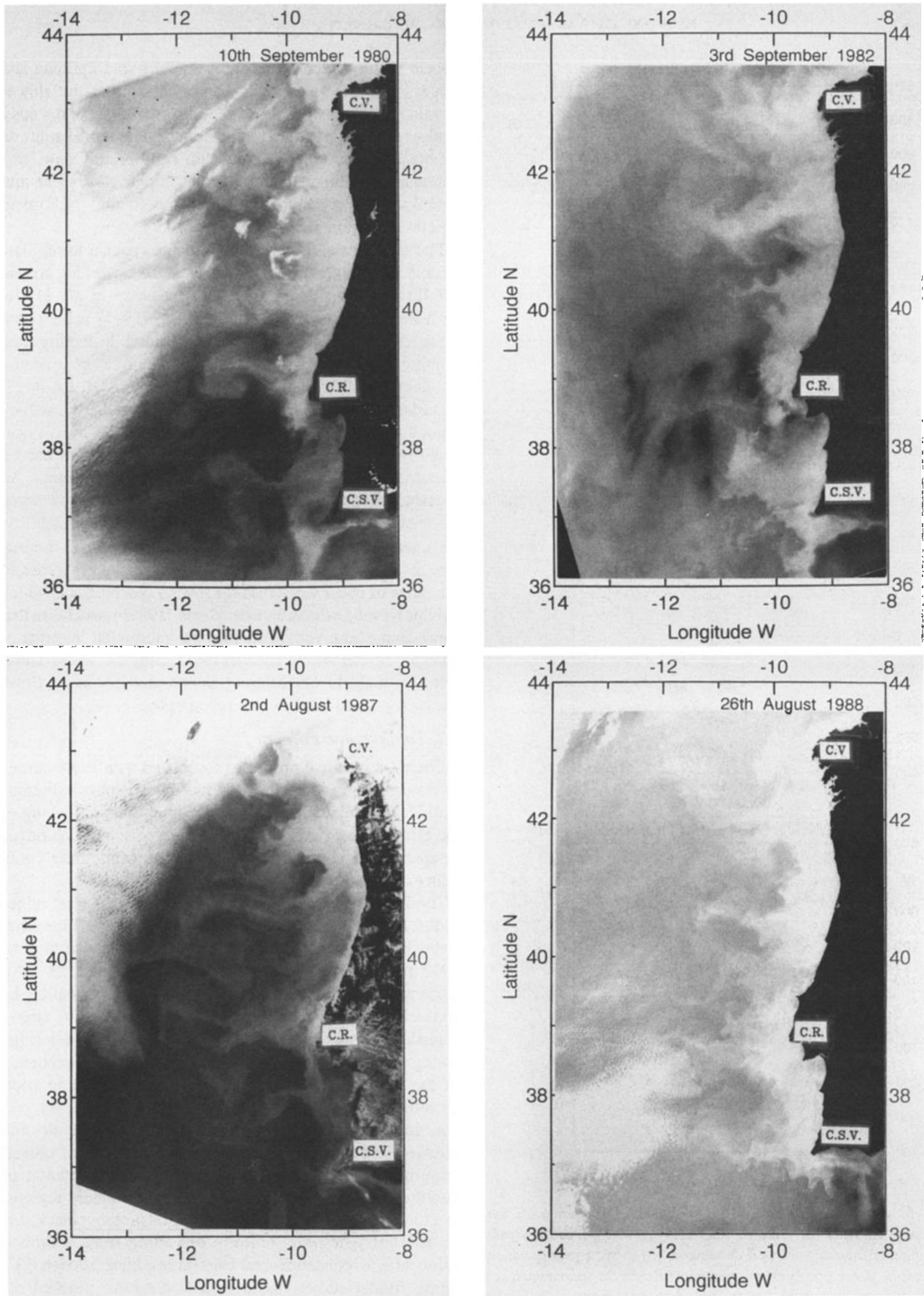

Fig. 5. A weries of satellite images from a number of different years showing the similarity in the gross features of the observed temperature field. However, the large interannual variations in the detailed temperature field are readily apparent. 

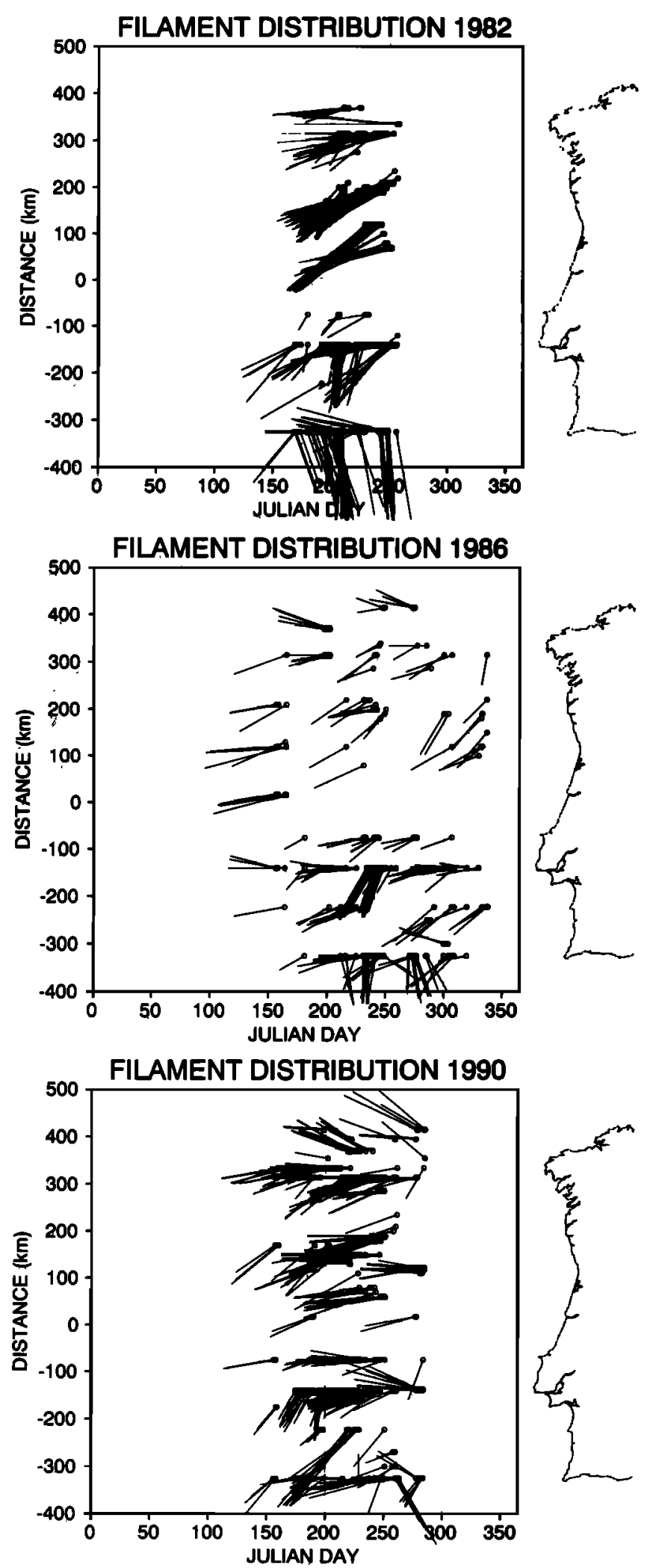

Fig. 6. Time series showing the evolution of filaments off the Iberian Peninsula for three representative years: (a) 1982, a year in which filaments were well developed; (b) 1986, a year in which filaments where poorly developed and episodic in appearance; (c) 1990, a year illustrating a more typical development.

generating an equatorward surface jet, a poleward undercurrent, and an upwelling front. Subsequently, after approximately $\mathbf{7 0}$ days, small-scale, fingerlike disturbances appear along the coast and grow rapidly in amplitude and scale. The growth in scale has two causes: the slower development of larger-scale disturbances and eddy coalescence via nonlinear interactions. The model solution eventually adjusts to a realistic equilibrium state that contains upwelling filaments, eddies, dipole eddy pairs, and a realistic mean circulation compared to the Califormian coastal transition zone.

The small-scale, fingerlike disturbances appear to simulate closely the features observed early in the upwelling season off Iberia (compare Figure 3 of McCreary et al., [1991] with Figure 2 here). McCreary et al., [1991] believe that these disturbances are a form of frontal instability that requires the existence of an upper layer temperature gradient. From simpler solutions of the model, the larger disturbances which result in filaments can be caused by baroclinic instabilities. However, model studies using linear stability models show that unstable wave solutions can be obtained Barth [1989a] for a coastal upwelling front. An unstable mode gains energy from the basic flow state associated with the upwelling front via baroclinic instability. This wave grows in the absence of any extemal forcing. The results of the stability model predict wave properties in the range of observed values for several coastal fronts which exhibit wavelike disturbances. Barth [1989b] concludes that some alongshore variability may be interpreted in terms of unstable frontal waves and that the stability of the upwelling front is likely to be different as the alongshore jet flows between regions of different topography.

\subsection{Topographic Forcing}

Coastal dynamical processes associated with irregularities of the coastline and shelf and induced wind stress variations could lead to filament formation. Separation or blocking of the alongshore coastal current by capes or submarine ridges or spatial and temporal variation of the wind stress could either one lead to strong offshore flow.

The Iberian region has three pronounced east-west ridges at the latitudes of the three major capes (Cape Finisterre, Cabo Roca, and Cabo Săo Vicente). These rise at least $2000 \mathrm{~m}$ above the deep abyssal plain (Figure 1). An equatorward flow over this topography would, by conservation of potential vorticity, be subject to strong meandering over and possibly downstream of the ridge owing to the topographic $\beta$ effect. Any offshore tendency of the flow as it encountered the ridge could drag cool, upwelled waters offshore to form a filament.

A series of studies summarized by Narimousa and Maxworthy [1989] applies laboratory modeling of coastal upwelling, using a rotating tank, to the interpretation of satellite and field observations in eastem boundary regions. In experiments without any major coastal protuberances, that is, capes and ridges, a uniform upwelling front is formed along with associated frontal baroclinic eddies (section 6.1). These frontal eddies, those eddies that have pinched off from the upwelling system, and the eddies preexisting offshore can all combine to produce a complex field. The structure of the eddies is two-dimensional and geostrophic, and when the eddies interact with the upwelling system, 


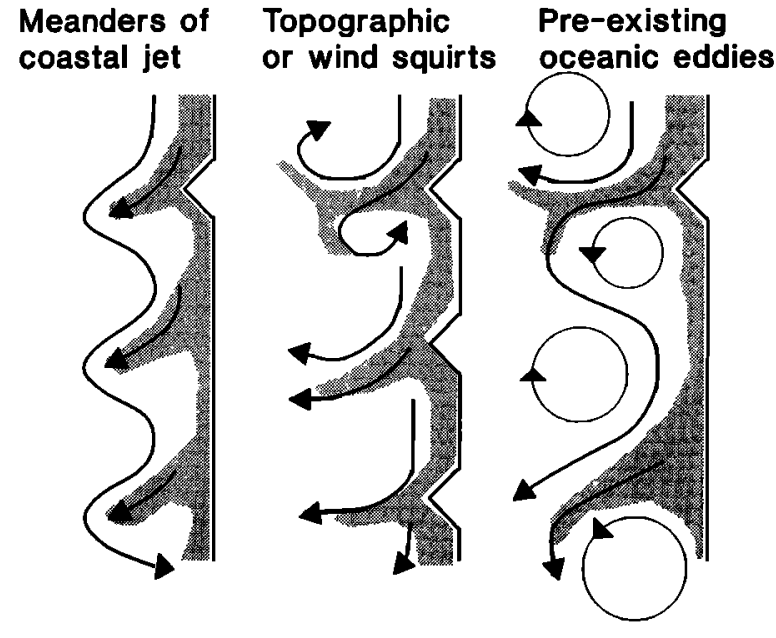

Fig. 7. The three conceptual models of filament formation [after Strub et al., 1991].

associated geostrophic jets can transport upwelled water offshore in the form of meandering filaments (section 6.3). In experiments that include coastal and shelf morphology (either cape or ridge), a standing wave is often found downstream. This suggests that filaments found near major capes and ridges can form as a result of the interaction between the coastal irregularities and the upwelling system. Laboratory experiments show that a ridge running offshore across the flow produces a meander centered over the ridge and standing waves downstream. This wave pattem may become unstable and grow in amplitude offshore, eventually releasing eddies into the ocean. The empirical criterion for instability is when a control parameter $\theta^{*}<6$. The control parameter is defined as

$$
\theta^{*}=g^{\prime} h_{0} / u^{*} \mathfrak{f l}_{\text {a }}
$$

where $g$ ' is reduced gravity, $h_{0}$ is the upper layer depth, $f$ is the Coriolis parameter, $\mathrm{u}^{*}$ is the surface friction velocity, and $\lambda_{1}$ is the undisturbed width of the upwelling region. Substituting reasonable values for Iberia (Table 2), it is found that $\theta^{*}-5$, indicating the likelihood of unstable meandering.

Rotating tank experiments also allowed derivation of an empirical formula to predict a number of the characteristics of the flow field. These include wavelength of the baroclinic instabilities of the upwelled front $L_{w}$, the size of the offshore eddies $\lambda_{b}$, the amplitude $A_{s w}$ and the distance downstream $D_{s w}$ of the first standing wave downstream of a cape or ridge, and the amplitude of the meander over the ridge $A_{\mathbf{s r}}$ The substitution of appropriate observed parameters from the imagery provides order of magnitude agreement with the dimensions and spacing of the filaments associated with the major capes and ridges (Table 2). Upper layer depth $h_{6}$ and density stratification are taken from in situ observations [Haynes and Barton, 1990]. Although no direct measurements of surface flow (hence $u^{*}$ ) in Iberian filaments are available, estimated translational speeds of surface features in AVHRR imagery sequences of a filament off Cabo Săo Vicente are around $15-20 \mathrm{~cm} \mathrm{~s}^{-1}$
(E.D. Barton et al., unpublished manuscript 1993). There is considerable difficulty in estimating the length scales, for example, the undisturbed width of the upwelling zone $\lambda_{s}$, in such a dynamic system, and the calculation results are prone to large error.

The laboratory model shows that baroclinic waves should begin to appear when the upwelled front has migrated an offshore distance of $\lambda_{1}$ given by

$$
\lambda_{1}=0.7 \theta^{*-0.5} \lambda_{\mathrm{a}}
$$

The substitution of field data gives a value of $\lambda_{1}=20 \mathrm{~km}$ for the minimum offshore distance of the upwelled front before baroclinic waves appear. In the satellite image of Figure 2, which shows the early stages of upwelling, small fingerlike disturbances with wavelengths of $10-20 \mathrm{~km}$ have already formed at about the distance predicted. In the absence of any external forces, the upwelled front migrates offshore until an equilibrium state is reached when the radial pressure gradient due to front deformation is balanced by the radial Coriolis force beneath the ageostrophic surface Ekman layer [Narimousa and Maxworthy, 1989]. The stationary upwelling front has frontal eddies of diameter $\lambda_{\text {w }}$ given as $\lambda_{w}=0.1 \theta^{*} \lambda_{3}$. This yields a value of $35 \mathrm{~km}$ for the Iberian coastal transition zone. Hence any filaments associated with the baroclinic instabilities will have a wavelength $L_{\mathrm{w}}$ of $2 \lambda_{\mathrm{w}}$, in this case approximately $70 \mathrm{~km}$. This wavelength provides order of magnitude agreement with the spacing of the observed filaments away from regions with marked topography.

In the case of ridges and capes, the stability of the amplitude of the standing waves generated is dependent on the value of the control parameter $\theta^{*}$. Since the estimated value of the control parameter off Iberia is approximately 5 , then the waves should be unstable and grow offshore, eventually becoming detached and forming cyclonic offshore eddies. The results obtained by applying the empirical formula derived from work by Narimousa and Maxworthy [1989] to Cape Finisterre and Cabo Roca are summarized in Table 2. In the case of Cape Finisterre, the first standing wave should lie between 70 and $130 \mathrm{~km}$ south of the cape; from the observations (Figure 4a) a filament is observed centered approximately $110 \mathrm{~km}$ south (at $200 \mathrm{~km}$ north). A further filament is located approximately another $80 \mathrm{~km}$ south (at $120 \mathrm{~km}$ north). The mean and maximum observed lengths of both these filaments are the longest recorded. This agreement between the observations and the empirical relations of Narimousa and Maxworthy seems to indicate that the large filaments observed along the relatively "smooth" northern Portuguese coast are formed as a consequence of unstable meanders instigated by the presence of Cape Finisterre.

According to the empirical relationships, in the case of Cabo Roca, filaments would be expected at 80 or $170 \mathrm{~km}$ south of the cape. Filaments are seen in the observations at approximately these distances south of the cape, but the situation is complicated because those distances roughly correspond to the positions of two other major capes. It is therefore impossible to distinguish whether these filaments 
TABLE 2. Application of Empirical Formula of Narimousa and Mexworthy, [1989] to the Iberian Coastal Transition Zone.

\begin{tabular}{|c|c|c|}
\hline & \multicolumn{2}{|c|}{ Value } \\
\hline \multicolumn{3}{|l|}{ Observed parameters } \\
\hline Upper layer depth $h_{6}$ & \multicolumn{2}{|l|}{$30 \mathrm{~m}$} \\
\hline Reduced gravity $\mathbf{B}^{\circ}$ & \multicolumn{2}{|c|}{$1.6 \mathrm{~cm} \mathrm{~s}^{-2}$} \\
\hline Surface friction velocity $\mathbf{u}^{*}$ & \multicolumn{2}{|c|}{$1.5 \mathrm{~cm} \mathrm{~s}^{-1}(u *-0.1 u)$} \\
\hline Coriolis parameter f & \multicolumn{2}{|c|}{$9.4 \times 10^{5} 8^{-1}$} \\
\hline Undisturbed upwelling width $\lambda_{2}$ & \multicolumn{2}{|l|}{$70 \mathbf{~ k m}$} \\
\hline \multicolumn{3}{|l|}{ Derived parameter } \\
\hline Control Parameter $\theta^{*}$ & \multicolumn{2}{|l|}{-5} \\
\hline Rossby $\boldsymbol{\beta}$ number $\mathbf{R}_{\boldsymbol{p}}$ & \multicolumn{2}{|l|}{-0.02} \\
\hline \multicolumn{3}{|l|}{ Baroclinic waves and frontal eddies } \\
\hline Minimum width of upwelled front & \multicolumn{2}{|l|}{$22 \mathrm{~km}$} \\
\hline Wavelength of frontal eddies & \multicolumn{2}{|l|}{$68 \mathrm{~km}$} \\
\hline Filament Scales & Cape Finisterre & Cape Roca \\
\hline \multicolumn{3}{|l|}{ Ridge Theory } \\
\hline Width of Ridge & $100 \mathrm{~km}$ & $50 \mathrm{~km}$ \\
\hline Height of Ridge & $3 \mathbf{~ k m}$ & $2 \mathbf{~ k m}$ \\
\hline Water depth & $4 \mathrm{~km}$ & $4 \mathrm{~km}$ \\
\hline Amplitude of wave over ridge & $150 \mathrm{~km}$ & $125 \mathrm{~km}$ \\
\hline Distance to first standing wave & $70 \mathbf{~ k m}$ & $80 \mathrm{~km}$ \\
\hline Amplitude of first standing wave & $130 \mathrm{~km}$ & $75 \mathrm{~km}$ \\
\hline \multicolumn{3}{|l|}{ Cape Theory } \\
\hline Radius of Cape & $30 \mathrm{~km}$ & $40 \mathrm{~km}$ \\
\hline Distance to first standing wave & $133 \mathrm{~km}$ & $168 \mathrm{~km}$ \\
\hline Amplitude of first standing wave & $105 \mathrm{~km}$ & $140 \mathrm{~km}$ \\
\hline
\end{tabular}

are due to unstable meandering forced by the presence of Cabo Roca or whether they are locally forced.

The effect of wind stress variations caused by coastal morphology on the surface flow may cause the generation of offshore flowing current jets. Jury [1985], in a study of upwelling off the SW tip of Africa, showed how wind stress shear due to topographic irregularities can have an effect on the coastal upwelling. The low-level winds accelerate around the major capes giving rise to enhanced upwelling. The existence of local variations in wind stress due to topographic forcing has been observed in the northem part of the region, where the steep-sided rias of Galicia channel the wind to the southwest [McClain et al., 1986]. However, to the south of Galicia, where the coastal morphology is much less rugged, this mechanism is not a likely candidate for driving the formation of filaments.

\subsection{Geostrophic Turbulence}

The interaction of eddies (geostrophic turbulence) with the coastal upwelling zone may lead to the formation of filaments. Mooers and Robinson, [1984] postulated that an eddy pair observed off northern Califomia acted as a "roller bearing" drawing a filament of cold water seaward. An oceanic eddy field with a length scale $O(100 \mathrm{~km})$ is known 
to exist in the Iberian region [Krauss and Böning, 1987; Haynes and Barton, 1991].

However, the deterministic nature of the filaments means that a truly random interaction of oceanic eddies with the coastal transition zone is not possible. In addition, the complicated bathymetry of the region could give rise to topographically generated eddies. The large seamounts that form the Galicia Bank and the Gorringe Bank may have associated Taylor columns, generated through the interaction of the mean current with the underlying topography [Huppert and Bryan, 1976]. As discussed above, eddies are also shed along baroclinically unstable fronts. It is therefore very difficult to determine from Eeld observations whether the eddies that interact with the upwelling region are truly oceanic in nature, have been generated by topographic effects, or have formed in situ as a result of baroclinic processes. The associated length scales of the three kinds of eddies are so similar $(O(100 \mathrm{~km}))$ that unless the origins of the eddies in the coastal transition zone can be determined from satellite imagery, the formation mechanisms will be impossible to separate.

\section{Discussion}

The three simple processes of formation described above are probably not mutually exclusive, particularly in a region of complex bathymetry and coastal topography such as the Atlantic coast of the Iberian Peninsula. The differing relative importance of each process determines the position and size of each filament. For example, coastal topography, bathymetry, or wind stress variations may initiate instabilities in the surface current field. These instabilities may grow and generate eddies which in tum interact with the coastal upwelling region to form filaments.

Although there is a lack of in situ observations of the filaments off Iberia, it is possible to use the satellite imagery to make educated guesses as to the major processes involved in the generation of individual filaments. From the observations presented in this paper, the major dynamical process involved in the generation of the Iberian filaments is coastal forcing, as the large majority of the observed filaments are seen to be associated with coastal promontories and capes. Looking at the filaments by region we can make a number of generalizations.

1. The filaments north of Cape Finisterre are all observed to be intimately associated with capes, and the dominant process involved in their formation is likely to be coastal forcing, either via the direct interaction of the near-surface current field with the topographic features or indirectly via variations in the wind stress caused by orographic effects. It is possible, however, that the large filament associated with Cape Ortegal and Cape Finisterre represents an "overshoot" of the coastal jet when upwelling occurs along the northem Spanish coast.

2. The filaments observed along the northem Portuguese coast between $+300 \mathrm{~km}$ and $-50 \mathrm{~km}$ which are not intimately associated with the presence of any large capes, are probably generated by instability processes initiated by the large capes to the north. This supposition is consistent with both numerical and laboratory modeling.

3. South of $-50 \mathrm{~km}$, the filaments are again observed to be topographically anchored to the major capes of the region. Therefore it is again hypothesized that the major dynamical process involved in the formation of these filaments is topographic forcing. It is possible, though, that the large filament observed at Cape São Vicente $(-330 \mathrm{~km})$, particularly when it has a north-south orientation, is formed as a consequence of the overshooting of the southerly coastal jet associated with upwelling along the Atlantic coast of the Iberian Peninsula.

\section{ConClusions}

From the analysis of the AVHRR satellite imagery presented in this paper, it is possible to draw the following conclusions about the development, persistence, and variability of upwelling filaments off the Iberian Peninsula.

In a typical year, upwelling starts in May or June, when a narrow band (often of uniform width) of colder water is observed to extend along much of the coast. This band of upwelled water often consists of many narrow fingers. As upwelling continues, nascent filaments are observed as bulges in the upwelling front; as long as active upwelling occurs, these bulges continue to evolve into filaments, which eventually reach their maximum length of approximately $250 \mathrm{~km}$ in late August and early September. In a typical year, however, growth of the filaments is not continuous and instead consists of periods of active growth interrupted by episodes when active upwelling ceases. In years when filament development persists uninterrupted for long periods (a month or longer) the filaments grow to the greatest lengths (over $250 \mathrm{~km}$ ). Such years are likely to be ones in which the Portuguese trade winds are welldeveloped. In years when filaments are poorly developed the Portuguese trades are likely to have been weak or interrupted by the passage of North Atlantic depressions.

There are typically five or six major filaments observed off the Iberian Peninsula when filaments are fully developed. Most of these filaments are associated with the major topographic features of the region, in particular the large capes which are common to the northern and southern parts of the peninsula. It is therefore highly probable that the dominant dynamical processes associated with filament formation off Iberia are related to topographic forcing. The exceptions are the two major filaments commonly observed along the "smooth" coastline of northern Portugal (between $250 \mathrm{~km}$ and $-50 \mathrm{~km}$ ). The dominant dynamical process involved in the formation of these filaments is flow instability resulting in meandering of the southward flowing current. These flow instabilities may be instigated by the large capes of northern Spain.

With the present lack of in situ observations in the Iberian coastal transition zone, it is not possible to distinguish the exact processes involved in the formation of each individual filament. It is probable that a number of different dynamical processes are involved in the formation of each 
individual filament. In a coastal transition region of complex bathymetry and coastal topography and with impinging oceanic eddies of indeterminate origin, such as exists off the Iberian Peninsula, it will require a major observational program before the major dynamical processes of the region become clear.

Acknowledgments. The authors would like to thank Bill Slade from the Institute of Terrestial Ecology, Bangor, for all his help with the image processing. Mark Abbott of Oregon State University provided valuable suggestions related to the statistical analysis of the filaments. We are also indebted to Peter Bayliss of the University of Dundee for providing the satellite imagery data. This project was funded by NERC grant GR3/5872.

\section{REFERENCES}

Afoneo Dias, C.M., A. Amorim, and M. das Dores Vacas, Seacurface temperature: Seavonal variation between the Iberian coast and the Madeirn Islands, 1981-1987, ICES Mar. Sci. Symp., 195, 177-186, 1992.

Barth, J.A, Stability of a coactal upwelling front, 1, Model development and a ability theorem, J. Geophys. Res., 94, 10,844-10,856, 1989a.

Barth, J.A, Stability of a coactal upwelling front, 2, Model results and comparien with obcervations, J. Geophys. Res., 94, $10,857-10,883,1989 b$.

Barton, E.D., Development of a dipole filament in the Iberian upwelling region (abstract), Eos Trans., AGU, 72(44), Fall Meeting auppl, 274, 1991.

Brink, KH. and TJ. Cowles, The Coantal Transition Zone Program, J. Geophys. Res., 96, 14,637-14,647, 1991.

Brink, K.H., R.C. Beardsley, P.P. Niiler, M. Abbott, A. Huyer, S. Ramp, T. Stanton, and D. Stuart, Statistical properties of nearourface flow in the Califomia coastal transition zone, J. Geophys. Res., 96, 14,693-14,706, 1991.

Davis, R.E., Drifter observations of coastal auface currents during CODE: The descriptive view, J. Geophys. Res., 90, 4741-4755, $1985 a$.

Davis, R.E., Drifter observations of coastal aurface currents during CODE: The statistical and dynamical views, J. Geophys. Res., 90, 4756-4772, $1985 b$.

Flament, P., L. Ami, and L. Washburn, The evolving structure of an upwelling filament, $J$. Geophys. Res., 90, 11,765-11,778, 1985.

Frouin, R., A.F.G. Fiuza, I Ambar, and T.J. Boyd, Observations of a poleward surface current off the coasts of Portugal and Spain during winter, J. Geophys. Res., 95, 679-691, 1990.

Haynes, R., and E.D. Barton, A polewand flow along the Atlantic coast of the Iberian Peninsula, J. Geophys. Res., 95, 11,425-11,442, 1990.

Haynes, R, and E.D. Barton, Lagrangian observations in the Iberian coastal transition zone, J. Geophys. Res., 96, 14,731-14,741, 1991.
Huppert, $\mathbf{H}$., and $\mathbf{K}$. Bryan, Topographically generated eddies, Deep Sea Res., 23, 655-679, 1976.

Huyer, A., P.M. Kosro, J. Fleischbein, S.R. Ramp, T. Stanton, L. Washbum, F.P. Chavez, T.J. Cowles, S.D. Pierce, and R.L, Smith, Currents and water masses of the coastal transition zone off northem California, June to August 1988, J. Geophys. Res., 96, 14,809-14,831, 1991.

Ikeda, M. and W.J. Emery, Satellite observations and modelling of meanders in the Califomia Current system off Oregon and northem Califomia, J. Phys. Oceanogr., 14, 1434-1450, 1984.

Jury, M., Wind shear and upwelling along the SW tip of Africa, in International Symposium on Upwelling off West Africa, Inst. Inv. Pesq., Barcelona 1985, 1, 149-159, 1985.

Kadko, D.C., L. Washbum, and B. Jones, Evidence of subduction within cold filaments of the northem Califomia coastal transition zone, J. Geophys. Res., 96, 14,909-14,926, 1991.

Kosro, P.M., and A. Huyer, CTD and velocity surveys of seaward jets off northem Califomia, July 1981 and 1982, J. Geophys. Res., 91, 7680-7690, 1986.

Krauss, W., and C.W. Böning, Lagrangian properties of eddy fields in the northern North Atlantic as deduced from satellitetracked buoys, J. Mar. Res., 45, 259-291, 1987.

McClain, C.R., S.-Y. Chao, L.P. Atkineon, J.O. Blanton, and F. de Cactillejo, Wind-driven upwelling in the vicinity of Cape Finisterre, Spain, J. Geophys. Res., 91, 8470-8486, 1986.

McClain, E.P., W.G. Pichel, and C.C. Walton, Comparative performance of AVHRR-based multichannel wea surface temperatures, J. Geophys. Res., 90, 11,587-11,601, 1985.

McCreary, J.P., Y. Futramachi, and P.K Kundu, A numerical investigation of jets and eddies near an eastern ocean boundary, J. Geophys. Res., 96, 2515-2534, 1991.

Mooers, CN.K, and AR. Robinson, Turbulent jets and eddies, Science, 223, 51-53, 1984.

Narimousa, S., and T. Marworthy, Application of a laboratory model to the interpretation of eatellite and field observations of coastal upwelling, Dyn. Atmos. Oceans, 13, 1-46, 1989.

Strub, P.T., P.M. Kosro, and A. Huyer, The nature of the cold filaments in the Califomia Current system, J. Geophy. Res., 96, 14,743-14,768, 1991.

Washbuum, L., D.C. Kadko, B.H. Jones, T. Hayward, P.M. Kosro, T.P. Stanton, S. Ramp, and T. Cowles, Water mase subduction and the transport of phytoplankton in a coastal upwelling zone, J. Geophys. Res., 96, 14,927-14,945, 1991.

Wooster, W.S., and J.L. Reid, Eastem boundary currents, in The Sea, Vol. 2, edited by M.N. Hill, 253-280, Interscience, New York, 1963.

E.D. Barton, R. Haynes, and I. Pilling, School of Ocean Sciences, University of North Wales, Menai Bridge, Gwynedd LL59 5EY, Wales.

(Received September 18, 1992; revised May 18, 1993; accepted June 9, 1993.) 